\title{
Recent advances in ground-based ultraviolet remote sensing of volcanic $\mathrm{SO}_{2}$ fluxes
}

\author{
Giancarlo Tamburello ${ }^{1}$, Andrew J. S. McGonigle ${ }^{2,3,{ }^{*}}$, Euripides P. Kantzas ${ }^{2}$, Alessandro Aiuppa ${ }^{1,3}$ \\ ${ }^{1}$ Università degli Studi di Palermo, Dipartimento DiSTeM, Palermo, Italy \\ ${ }^{2}$ University of Sheffield, Department of Geography, Sheffield, UK \\ ${ }^{3}$ Istituto Nazionale di Geofisica e Vulcanologia, sezione di Palermo, Palermo, Italy
}

Article history

Received October 8, 2010; accepted March 3, 2011.

Subject classification:

Volcanology, Volcanic Gases, Volcano monitoring, Volcanic effects upon atmosphere, Atmospheric instruments and techniques.

\section{ABSTRACT}

Measurements of volcanic $\mathrm{SO}_{2}$ emission rates have been the mainstay of remote-sensing volcanic gas geochemistry for almost four decades, and they have contributed significantly to our understanding of volcanic systems and their impact upon the atmosphere. The last ten years have brought stepchange improvements in the instrumentation applied to these observations, which began with the application of miniature ultraviolet spectrometers that were deployed in scanning and traverse configurations, with differential optical absorption spectroscopy evaluation routines. This study catalogs the more recent empirical developments, including: ultraviolet cameras; wideangle field-of-view differential optical absorption spectroscopy systems; advances in scanning operations, including tomography; and improved understanding of errors, in particular concerning radiative transfer. Furthermore, the outcomes of field deployments of sensors during the last decade are documented, with respect to improving our understanding of volcanic dynamics and degassing into the atmosphere.

\section{Introduction}

Volcanic gases have very important roles in driving manifested activities, whether these involve passive release of these volatiles from summit craters, or pressurization to generate violent paroxysms. Furthermore, measurements of these gases provide important information on underground conditions, enabling the definition of, for instance, the masses of underground magmatic bodies, defining whether these are rising or falling, or if a system is sealed, or whether hydrothermal interactions are involved. Such data have therefore been implicit in the activities of volcano monitoring, with data concerning emitted gas ratios and emission rates contributing significantly to hazard assessment endeavours at a number of targets worldwide [e.g., Aiuppa et al. 2007, Olmos et al. 2007, Arellano et al. 2008].

These volatiles are also highly significant with respect to their impact upon the atmosphere, both chemically and radiatively. Released $\mathrm{SO}_{2}$ reacts to form sulfate aerosol droplets, which back-scatter incident solar radiation, so increasing the albedo of the Earth. Better constraints upon volcanic loading of the atmosphere, both temporally and spatially, are therefore highly important in terms of improving climate models. Furthermore, when entrained at ground level, acidic gas species can have deleterious impacts upon ecosystems, a prominent example of which was the 1783-1874 eruption of the Laki Fissure in Iceland, in which pasturelands and fields were severely fumigated, with catastrophic consequences [Thordarson and Self 2003].

Traditionally, volcanic gas studies have been conducted by collecting samples manually from active vents and craters; for instance, by bubbling the volatiles through alkaline solutions, then transporting these to the laboratory, where the analyses are carried out [e.g., Symonds et al. 1994]. While this provides very detailed geochemical information, the requirement of access does pose risks and precludes observations during elevated eruptive periods. Furthermore, characterization of individual fumaroles might not be representative of the degassing characteristics of a volcano as a whole. In response, scientists have increasingly adopted remote sensing during recent decades, which involves measurements of the bulk plume and which can provide high temporal resolution and near real-time processed data. These are of great value during activity crises. Finally, these techniques are also applicable many kilometers from a source, thus allowing for far greater safety, even during eruptions.

Volcanic gas remote sensing is mainly predicated upon the absorption of radiation by the volatile species, from which gas emission rates and chemical compositions are inferred [McGonigle 2005]. The most ubiquitously used spectral window for these observations has been the ultraviolet (UV) [Oppenheimer 2010]. This has largely concerned down-scattered solar radiation that is sampled 
from the ground to assess $\mathrm{SO}_{2}$ emission rates. Following on from 30 years of valued service in this application area, the previously used correlation spectrometers [Moffat and Millán 1971, Stoiber et al. 1983] were upgraded some 10 years ago to miniature UV USB-powered grating spectrometers, and in particular the Ocean Optics Inc. USB2000 [e.g., McGonigle et al. 2002, Galle et al. 2003, Horton et al. 2006, McGonigle 2007, Kantzas et al. 2009]. In an earlier study [Kantzas and McGonigle 2008], we summarised how these USB2000 units are used to assess $\mathrm{SO}_{2}$ emission rates in standard scanning and traversing configurations, covering the associated differential optical absorption spectroscopy (DOAS) evaluation routines [e.g., Platt et al. 1979, Platt and Stutz 2008]. In the present study, we go further, through reviewing the outcomes of field installations of these units, with the aim to improve our understanding of volcanic dynamics and degassing into the atmosphere. In addition, more recent empirical developments in the remote sensing of UV volcanic plumes are discussed, including: ultraviolet cameras; wide-angle field-of-view DOAS systems; advances in scanning operations, including tomography; and improved understanding of errors, and in particular those concerning radiative transfer.

It should also be noted that a considerable and increasing volume of work that is not covered here has also been performed in the infrared, using Fourier transform infrared spectroscopy, to derive plume-gas ratios, from which the source depths of the degassing have been inferred. This has led to substantial advances in the understanding of volcanic systems [e.g., Edmonds 2008]. However, the UV sensors are cheaper and involve simpler retrievals, and hence they have been more widely used. In addition to these ground-based configurations, UV techniques have also been applied from satellite platforms, such as total ozone mapping spectrometry and ozone monitoring instruments, which have been largely focused on the need to define volatile inputs to the atmosphere, with uses including the quantification of global climatic and chemical impacts and for aviation-hazard mitigation [e.g., Krotkov et al. 2006]. Whereas in the past only the release of explosive gases was resolvable, due to improvements in sensor technology, passive degassing can now also be measured under favorable conditions. Notwithstanding this, high time resolution, high spatial resolution and low detection limits are more achievable from the ground, such that in the UV, this arrangement has been the focus of efforts that are aimed at studying volcanic dynamics.

\section{Field operations - investigating volcanic dynamics}

Miniature UV spectrometers have been widely deployed on volcanoes, both internationally in the context of field campaigns (e.g., as shown in Figure 1), and for routine operations by volcano observatories. This has provided insights into the dynamics at a number of target sites of varying magmatic compositions and eruptive styles. For instance, Arellano et al. [2008] reported elevated gas fluxes during the explosive activity phases at Tungurahua volcano, Ecuador, and more gas released than can feasibly be contained in the erupted magmas; they thus postulated that the additional volatiles might arise from exsolution from magma batches that overturn convectively within the conduit. Olmos et al. [2007] detailed enhanced $\mathrm{SO}_{2}$ release in line with increased seismicity in advance of the eruptions at Santa Ana volcano, El Salvador, as well as modulation of outgassing, which is also potentially related to convection or to tidal processes. Periodic fluctuations in gas release over timescales as short as $\approx 10 \mathrm{~min}$ have also been investigated for Erebus volcano in Antarctica, with respect to open-system degassing dynamics through the lava lake [Sweeney et al.
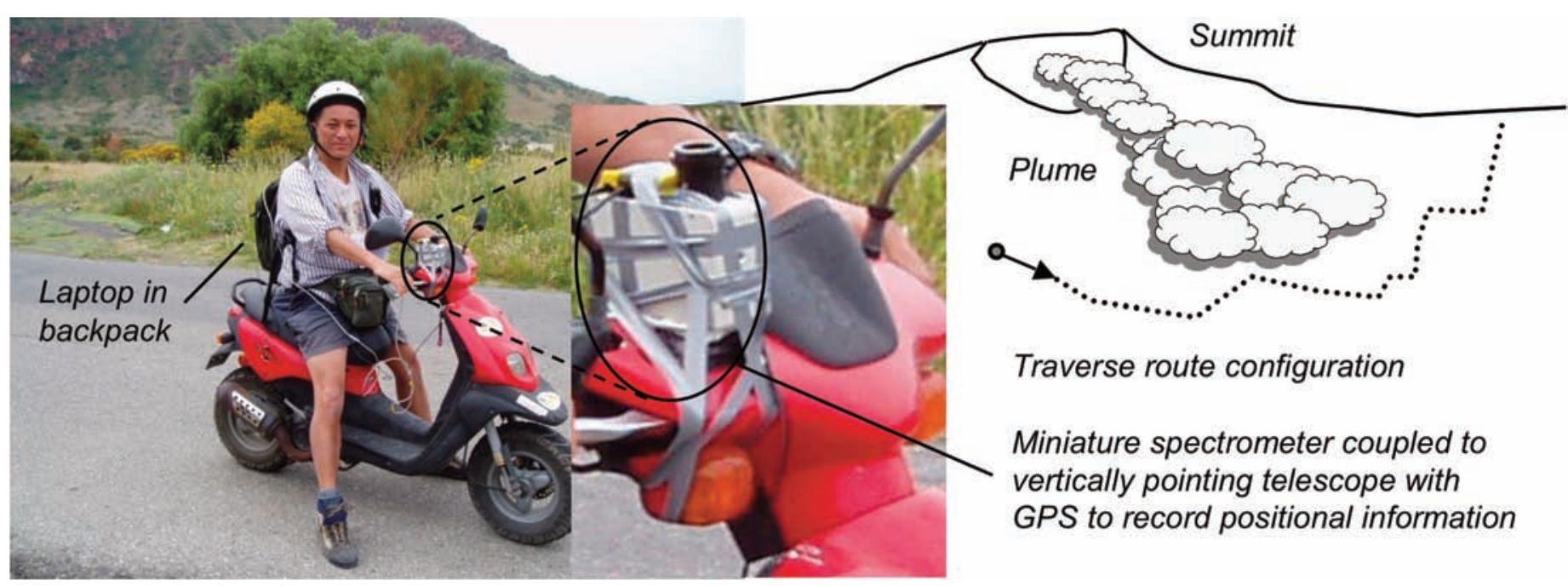

Traverse route configuration

Miniature spectrometer coupled to vertically pointing telescope with GPS to record positional information

Figure 1. Left - $\mathrm{SO}_{2}$ flux measurements performed via motorcycle traverses on roads downwind of La Fossa crater, Vulcano. Inset - Instrumentation used: laptop-computer-controlled miniature (USB2000) UV spectrometer, coupled to a vertically pointing telescope, and a GPS unit for geo-referencing. Right - Schematic drawing of traverse route beneath the volcanic plume. Gas fluxes are obtained by integrating the recorded $\mathrm{SO}_{2}$ column amounts over the plume cross-section, then multiplying by the plume transport speed. 

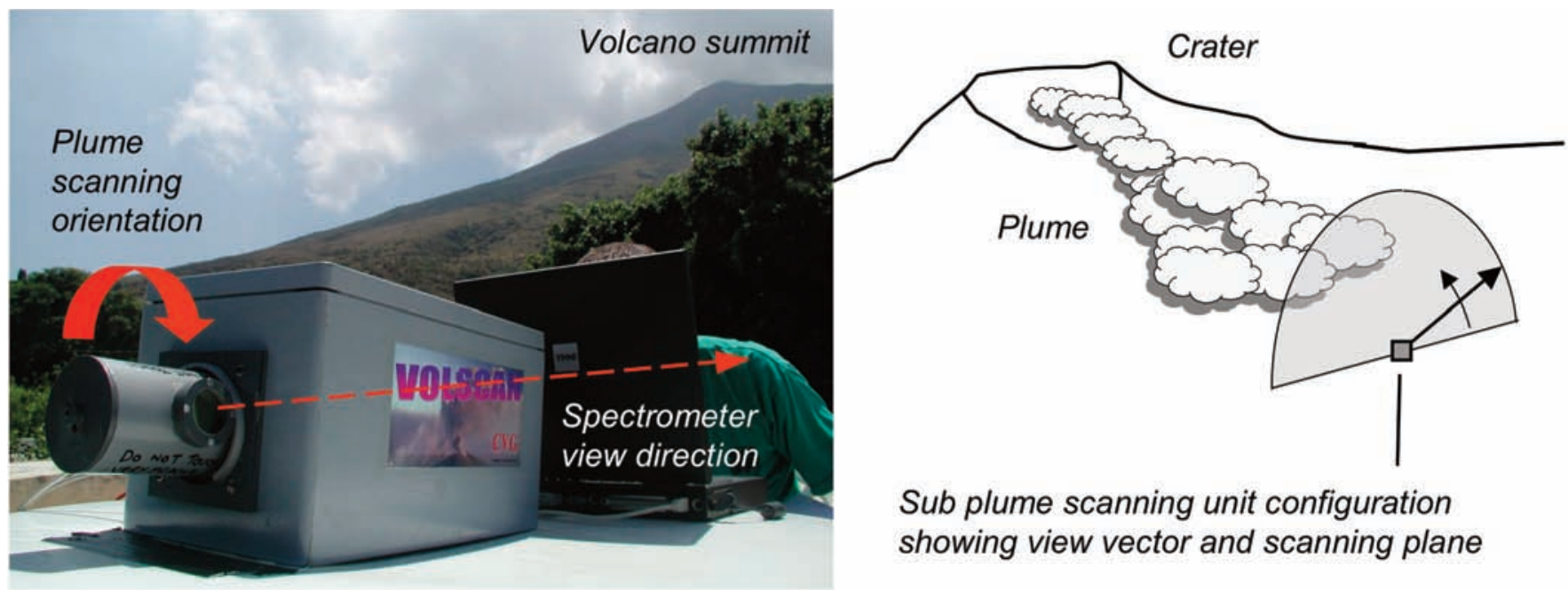

Figure 2. Left - Computer-controlled scanning unit situated beneath the plume of Stromboli volcano during $\mathrm{SO}_{2}$ flux measurements. Right - Schematic representation of the scanning configuration, showing the scan plane inclined nearly perpendicular to the wind direction.

2008]. Furthermore, magma-crater-lake interactions at Ambae volcano, Vanuatu, were studied by Bani et al. [2009b] using miniature spectrometer data, for recent surtseyan activity and changes in lake coloration.

Burton et al. [2009] reported elevated fluxes from Stromboli volcano, Italy, during the 2007 eruption, which were proposed to arise from the conduit containing a higher ratio of ascending-degassing to descending-degassed magmas than is usually the case. A decrease in the flux immediately prior to the March 15, 2007, paroxysm was proposed to have arisen from a collapse in the permeable gas escape network. This left volatile rich magma pockets at depth that ultimately coalesced and rose, and culminated in the explosion. Finally, a transition in the activity of Soufrière Hills volcano, Montserrat, was studied, whereby, following on from five vulcanian events, at the anticipated time of the sixth, a strong degassing event was observed instead [Edmonds and Herd 2007]. This was proposed to arise from crystallization and degassing in the upper conduit that caused radial gradients in viscosity and magma flow rates, and lead to brittle failure at the walls that formed a permeable shear zone through which gas could escape effusively rather than being explosively pressurized.

\section{Field operations - constraining atmospheric impacts}

Miniature spectrometer field deployments have also led to many data points that have enhanced the definition of the spatial and temporal volcanic volatile loading into the atmosphere, e.g., from Japan [Mori et al. 2006a], the Marianas [Hilton et al. 2007], Hawaii [Elias et al. 2006], central America [Mather et al. 2006, Barrancos et al. 2008], Papua New Guinea [McGonigle et al. 2004a], Italy [Aiuppa et al. 2005a, Aiuppa et al. 2005b, Bagnato et al. 2007, Aiuppa et al. 2008], Ethiopia [Oppenheimer et al. 2004, Sawyer et al. 2008a], Chile [Mather et al. 2004], the Democratic Republic of Congo [Sawyer et al. 2008b], Mexico [Grutter et al. 2008],
Antarctica [Oppenheimer et al. 2005, Sweeney et al. 2008] and Vanuatu [Bani et al. 2009a]. These reports do not only focus on $\mathrm{SO}_{2}$, however, with many of them using collated $\mathrm{SO}_{2}$ flux data in parallel with contemporaneously obtained gas-composition ratios (e.g., $\mathrm{X} / \mathrm{SO}_{2}$ ). These have been derived from various additional techniques, allowing the emission rates of other volcanic species to be inferred (e.g., $\mathrm{X}$ as $\mathrm{H}_{2} \mathrm{~S}, \mathrm{Hg}$ or $\mathrm{H}_{2} \mathrm{O}$ ). In particular, an unmanned aerial vehicle has been used in this way to remotely determine $\mathrm{CO}_{2}$ emission rates, which allow for deeper geochemical investigations of magmatic systems than the $\mathrm{SO}_{2}$ data [McGonigle et al. 2008].

The spectral ranges of the miniature spectrometers also overlap the wavelengths at which the differential absorption cross-sections of additional volcanogenic species are sufficiently strong to allow detection, as has been achieved using either diffuse skylight or various active sources, e.g., via a deuterium lamp to measure volcanic $\mathrm{H}_{2} \mathrm{~S} / \mathrm{SO}_{2}$ ratios [O'Dwyer et al. 2003]. BrO [Bobrowski et al. 2003, Oppenheimer et al. 2006, Bobrowski and Platt 2007, Kern et al. 2009], $\mathrm{ClO}$ [Lee et al. 2005] and OClO [Bobrowski et al. 2007] have been detected in addition. These halogen oxide observations have been particularly exciting, as the presence of these species implies halogen-catalyzed ozone depletion, which was subsequently reported empirically for tropospheric plumes by Vance et al. [2010]. Hence volcanic plumes are now believed to be far more than passive sources of volatile outgassing; they can also host a suite of novel and fascinating atmospheric chemical processes [e.g., Mather 2008].

\section{Developments in scanning operation}

One of the first capabilities to arise from the volcanological implementation of miniature spectrometers was the scanning configuration that enabled flux measurements in a matter of minutes from fixed positions below a plume, e.g., as shown in Figure 2, thus vastly improving on time resolution relative 
to the conventional traversing approach [e.g., Edmonds et al. 2003, McGonigle et al. 2003]. A number of volcanoes are now monitored using networks of these systems that have been installed to capture the plume under all wind directions, and are automated to provide near real-time fluxes throughout the daylight hours [e.g., Salerno et al. 2009a]. Much of the data discussed above have been captured in this way. Of particular note here has been the activity of the European Community Network for Observation of Volcanic and Atmospheric Change project, which has led to widespread dissemination of these systems to 18 volcanoes worldwide [Galle et al. 2010]. In certain cases, novel spectral retrievals have been implemented in which the reference spectrum is modeled, to account for scenarios where the entire scanning track of an instrument intersects the monitored plume, such that it is not possible to empirically characterize the background illumination [Salerno et al. 2009b].

Scanner network data have also been used to tomographically define two-dimensional profiles of the cross-sectional $\mathrm{SO}_{2}$ concentration distributions of plumes [Wright et al. 2008, Johansson et al. 2009a]. This has also been

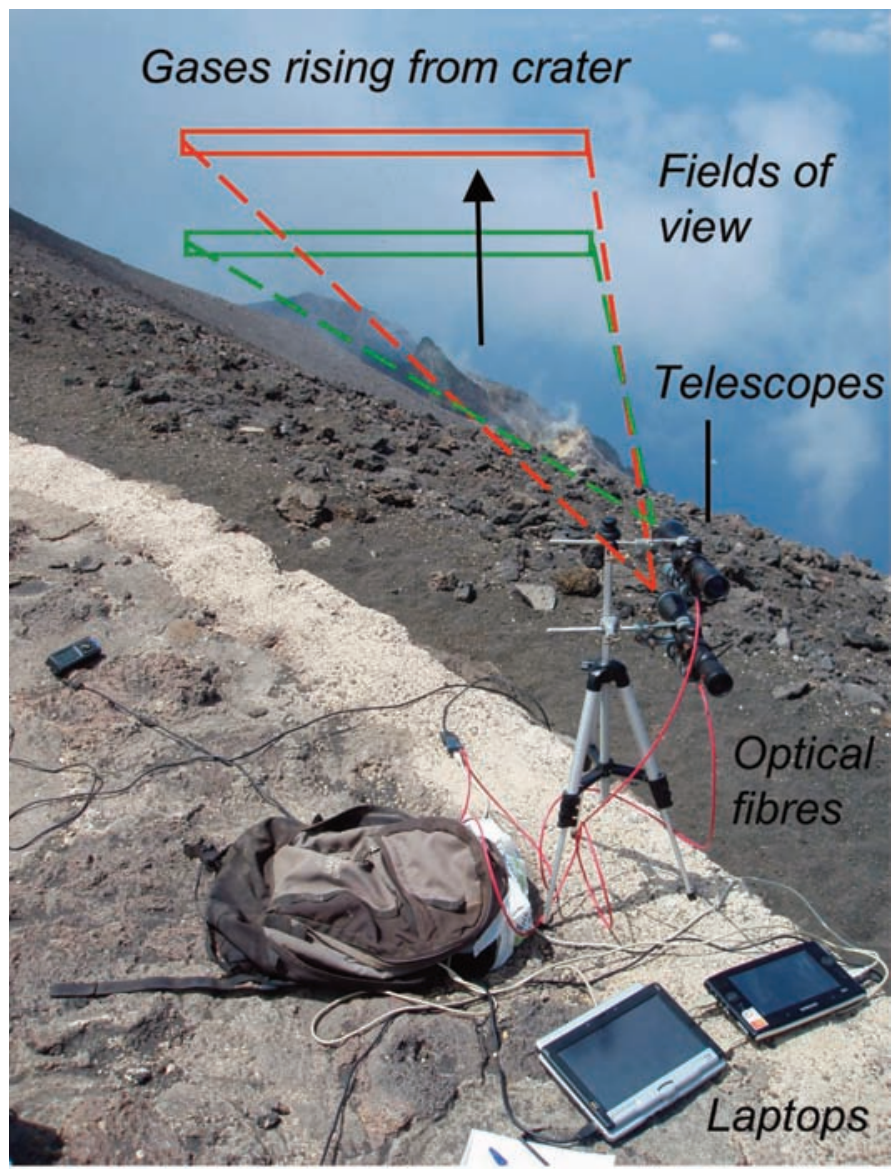

Figure 3. Configuration of the wide-angle field-of-view DOAS approach to determine high-time-resolution volcanic $\mathrm{SO}_{2}$ fluxes, as applied to the rising plume from Stromboli volcano. The orientation of the telescopes, and their quasi-rectangular fields of view are shown, in addition to the fiber connections to the miniature UV spectrometers and the controlling laptops. Note that the spectrometers themselves are concealed within the shade of the backpack. realized using a number of miniature spectrometers during under plume flights, each with a different viewing orientation [Kazahaya et al. 2008]. A variety of reconstruction algorithms and scanner-plume orientations have been considered, and reasonable agreement has been found between flux estimates from the conventionally processed raw scanner data and via summation of tomographically derived concentrations over a plume. The ability of tomography to define the limits of a plume can be used to militate against volcanic gas-related hazards, in particular concerning aviation. Finally, twodimensional imaging of volcanic plumes from a transverse vantage point has been achieved by scanning horizontally with a vertical array of spectrometers across the field of view of interest, via the so-called imaging DOAS approach [Bobrowski et al. 2006]. Louban et al. [2009] used this technique to investigate halogen chemistry in volcanic plumes, via the retrieval of the $\mathrm{SO}_{2}$ and $\mathrm{BrO}$ abundances.

\section{Wide-angle field-of-view DOAS observations}

Very recently, novel UV approaches have been developed that can acquire gas fluxes with far higher time resolution (of the order of $1 \mathrm{~Hz}$ ) than is possible even with scanning systems. One such technique involves two miniature spectrometers, each of which is coupled to a cylindrical lens telescope with quasi-rectangular fields of view that encompass the width of a rising or horizontally advecting plume. Their fields of view are separated by a small vertical angle in the former case (rising), and a small horizontal angle in the latter (horizontally advecting). Each spectrum from these devices therefore captures a proxy for the average concentrations across the field of view at a rate of about once per second. By multiplying these data by the width of the field of view, the so-called integrated column amounts (ICAs) can be obtained through a more rapid alternative to traversing or scanning, where ICAs are computed by summing the concentrations from the individual spectra over the cross-section of the plume. The plume speed is derived via the cross-correlation method, as detailed previously [e.g., McGonigle et al. 2005a, McGonigle et al. 2005b, Williams-Jones et al. 2006; Johansson et al. 2009b]. As usual, the fluxes are found by multiplying together the plume speed and the ICA data.

This approach has been deployed on Stromboli volcano, Italy [McGonigle et al. 2009], e.g., as shown in Figure 3, and Erebus in Antarctica [Boichu et al. 2010]; in the latter case, to study the gas phase and magmatic dynamics of the lava lake. For Stromboli volcano, individual Strombolian explosive events were resolved and their eruptive masses were defined. The gas flux data were also supported by the $1 \mathrm{~Hz}$ geophysical records in a non-aliased sense, showing clear correlations between the gas flux, and the thermal and seismic traces. Such an achievement is potentially very important for observational volcanology, in the sense that 


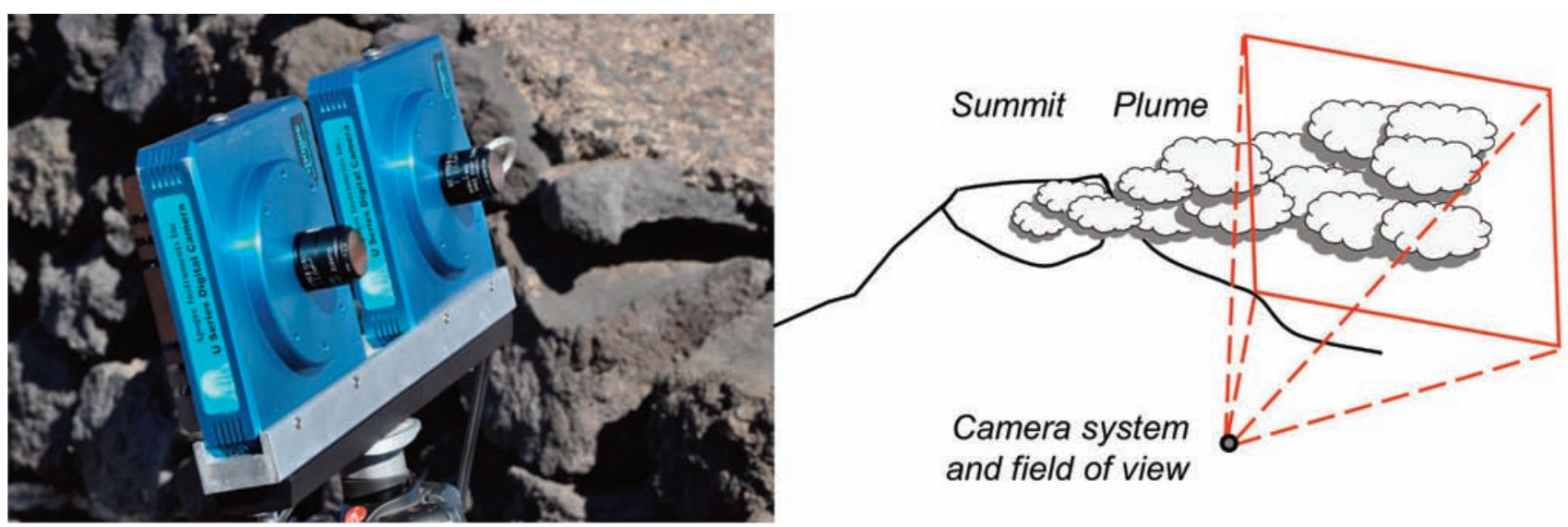

Figure 4. Left - Ultraviolet camera pair with bandpass filters at $310 \mathrm{~nm}$ and $330 \mathrm{~nm}$, tripod-mounted during a field campaign on Mt. Etna. Right Schematic configuration of a typical camera-viewing inclination, such that the field of view captures the plume from the side as it moves horizontally, downwind of the volcano.

the previously derived scanned or traversed gas fluxes had relatively lower time resolution, which limited the possibility of understanding rapid volcanic events in the most holistic combined geophysical and geochemical manner. Notwithstanding the possibilities of this approach, there are errors, as detailed by McGonigle et al. [2009] and Boichu et al. [2010]. These are associated with high gas concentrations, and where the gas plume only fills a relatively small portion of the width of the field of view, although these do need to be considered operationally.

\section{UV cameras}

Ultraviolet camera technology has also been applied to the capture of data for $\mathrm{SO}_{2}$ fluxes on the order of the $1 \mathrm{~Hz}$ time resolution (e.g., Figure 4) [Mori and Burton 2006, Bluth et al. 2007]. These units typically capture images of the plume through narrow-band transmission filters that are centered at around $310 \mathrm{~nm}$ and $330 \mathrm{~nm}$. The filters can either be mounted, one apiece, in front of the fore-optics of two cameras, or on a single camera in combination with a filter wheel. In the 310-nm spectral region, the plume $\mathrm{SO}_{2}$ absorbs radiation, in that of $330 \mathrm{~nm}$, it does not. Hence, by comparing the pixel intensities of the $310 \mathrm{~nm}$ and $330 \mathrm{~nm}$ plume images a measure is obtained of the optical density of the $\mathrm{SO}_{2}$ across the field of view. These data are converted to gas column density via a calibration relationship, which is normally determined by measuring the absorbance observed for a series of quartz cells containing known $\mathrm{SO}_{2}$ column amounts, and plotting these known column densities against the measured optical densities. The fluxes are obtained from the cameras by summing the concentrations across a line of pixels to generate the ICA. The plume speeds are defined by observing the rate at which the plume transects the field of view in a series of images. The high temporal resolution of the cameras has allowed investigations of a number of transient volcanic phenomena, ranging from quantifying gas masses released during strombolian explosions [Mori and Burton 2009, Dalton et al. 2010], to probing the dynamics of vulcanian plumes [Yamamoto et al. 2008]. Furthermore, the imaging ability has enabled the characterization of emissions across heterogeneous fumarole field sources at the La Fossa crater, Vulcano island [Tamburello et al. 2011].

By virtue of their high time resolution, ease of alignment and operation, and relatively low cost (starting from around $\$ 8,000$ ), the use of these cameras represents a highly promising technique in volcanology. This being said, as the approach is spectrally broadband, great care is required concerning the operating protocols, as without finer spectral information, a series of error sources can go uncorrected, as investigated by Dalton et al. [2009], Kantzas et al. [2010] and Kern et al. [2010a]. These reports considered factors such as the calibration relationship varying as a function of the solar zenith angle, the total $\mathrm{O}_{3}$ column, the filter illumination angle, and the volcanic plume $\mathrm{SO}_{2}$ concentration, as well as the scattering of radiation within the plume, or between the plume and the observer. A number of recommendations have been posited as a result, including: (i) that it is important to use two filters rather than just one at around $310 \mathrm{~nm}$, to characterize and correct for attenuation related to the aerosol phase with the $\approx 330 \mathrm{~nm}$ filter; (ii) that co-aligned DOAS miniature spectroscopic observations can be used to correct for radiative transfer effects in the $\mathrm{SO}_{2}$ concentrations determined by the camera; (iii) that appropriately chosen fore-optics will minimize the effects of the calibration that varies as a function of the illumination angle, or that calibration coefficients can be characterized for each pixel across the field of view of the camera; and (iv) that frequent empirical calibration in field or modeling efforts can be used to allow for changes in the calibration relationship due to the environmental factors detailed above.

\section{Studies into errors}

Recent years have also seen a number of studies concerning the sources of errors associated with $\mathrm{SO}_{2}$ flux measurements, which have been aimed at improving 
measurement accuracy. In particular, the assumption implicit in the flux computation that radiation is scattered downwards from above the plume while retaining straight photon paths until captured by the telescope has been reassessed. Indeed, to varying degrees, this situation is rather more complicated, with scatter occurring both within the plume and between the plume and the instrument, which can lead to significant overestimation or underestimation in the measurements, potentially by several hundred percent and $>70 \%$, respectively, according to Kern et al. [2010b]. With the correct implementation of correlation methods to reduce plume-speed-related errors [e.g., McGonigle et al. 2005a, McGonigle et al. 2005b, Williams-Jones et al. 2006], these radiative transfer issues become the dominant source of uncertainty in the flux measurements.

These optical-path-related effects depend upon factors such as the absorbing gas concentration within the plume, the plume and the ambient atmosphere aerosol conditions, and the plume-measurement distance. Mori et al. [2006b] and Kern et al [2010b] have studied these, and as a consequence, they reported that the apparent retrieved column amounts vary with wavelength, as a consequence of the spectrally dependent nature of the magnitudes of the $\mathrm{SO}_{2}$ absorption and scattering effects. These dependencies need to be accommodated into the measurement protocol, therefore, either using only the longest section of the UV $\mathrm{SO}_{2}$ absorption band in the fitting, where scatter between the plume and detector is the weakest, or using comparisons of field-observed absorbances with model results. A further proposed solution is to use a relatively longer wavelength band $(360-390 \mathrm{~nm})$ for retrievals than is normally applied [Bobrowski et al. 2010]. Future avenues of research will involve using spectral information to define microphysical information on aerosol conditions, to further limit this problem.

Another error source that has been investigated recently with these miniature spectrometers relates to the possibility that during the transit from the source, and prior to the remotely sensed measurement, the released $\mathrm{SO}_{2}$ can oxidize to form sulfate aerosols. This can lead to underestimation of the true source strength. To this end, an empirical link has been sought between the measured gas fluxes and the plume age in a number of studies [e.g., McGonigle et al. 2004b, Rodriguez et al. 2008]. With McGonigle et al. [2004b], for the Masaya volcano, Nicaragua, this effect was shown to be negligible, while with Rodriguez et al. [2008], for the Soufrière Hills volcano, Montserrat, a relatively more pronounced temporal depletion of the gas flux was reported. Additional investigations may further expedite our understanding here; however, as emphasized by Nadeau et al. [2009], it is imperative that instrumental and measurement factors that can cause apparent losses are eliminated.

\section{Conclusions}

The last decade has seen extraordinary advances in our ability to remotely monitor volcanic gas emissions in the UV, with respect to the adaptation of miniature USB spectrometers, and UV cameras in this application area. It is now possible to take measurements faster, more accurately, covering more chemical species, and at far lower prices than previously possible, which has resulted in the rapid proliferation of these units at volcanoes worldwide. This has led to significant advances with respect to our understanding of volcanic dynamics and the impact of volcanism upon the atmosphere, with a great prospect for further discoveries in the decades to come. With permanently installed scanning units, for instance, coupled with the stalwart efforts of volcano observatories, entirely unprecedented long-term degassing datasets are now emerging. This information will prove invaluable for monitoring and forecasting purposes. Future areas of study on the metrological side should focus on further reductions of the associated errors, with respect to the scattering issues. Regarding volcanic dynamics, a very promising prospect is seen by the emerging possibility of supporting high-time-resolution, 1-Hz, UV-camera gas fluxes with contemporaneous geophysical datasets, which should furnish us with far broader perspectives on a range of rapid degassing-driven or -related processes than was possible previously.

Acknowledgements. AMcG gratefully acknowledges Research Councils UK for an Academic Fellowship, the Istituto Nazionale di Geofisica e Vulcanologia (INGV) sezione di Palermo, and the Royal Society (Grant RG072241) for supporting this work. EPK thanks the AXA Research Fund for a Post-Doctoral Fellowship. We thank Salvo Inguaggiato and an anonymous reviewer for their extremely careful and helpful comments, which improved the quality of the manuscript enormously.

\section{References}

Aiuppa, A., C. Federico, A. Franco, G. Giudice, S. Gurrieri, S. Inguaggiato, M. Liuzzo, A.J.S. McGonigle and M. Valenza (2005a). Emission of bromine and iodine from Mount Etna volcano, Geochem. Geophys. Geosyst., 6, Q08008; doi: 10.1029/2005GC000965.

Aiuppa, A., S. Inguaggiato, A.J.S. McGonigle, M. O'Dwyer, C. Oppenheimer, M.J. Padgett, D. Rouwet and M. Valenza (2005b). $\mathrm{H}_{2} \mathrm{~S}$ fluxes from Mt. Etna, Stromboli, and Vulcano (Italy) and implications for the sulfur budget at volcanoes, Geochim. Cosmochim. Acta, 69, 1861-1871; doi: 10.1016/j.gca.2004.09.018.

Aiuppa, A., R. Moretti, C. Federico, G. Giudice, S. Gurrieri, M. Liuzzo, P. Papale, H. Shinohara and M. Valenza (2007). Forecasting Etna eruptions by real-time observation of volcanic gas composition, Geology, 35, 1115-1118; doi: 10.1130/G24149A.1.

Aiuppa, A., G. Giudice, S. Gurrieri, M. Liuzzo, M. Burton, T. Caltabiano, A.J.S. McGonigle, G. Salerno, H. Shinohara and M. Valenza (2008). Total volatile flux from Mount 
Etna, Geophys. Res. Lett., 35, L24302; doi: 10.1029/2008 GL035871.

Arellano, S.R., M. Hall, P. Samaniego, J.-L. Le Pennec, A. Ruiz, I. Molina and H. Yepes (2008). Degassing patterns of Tungurahua volcano (Ecuador) during the 1999-2006 eruptive period, inferred from remote spectroscopic measurements of $\mathrm{SO}_{2}$ emissions, J. Volcanol. Geotherm. Res., 176, 151-162; doi: 10.1016/j.jvolgeores.2008.07.007.

Bagnato, E., A. Aiuppa, F. Parello, S. Calabrese, W. D'Alessandro, T.A. Mather, A.J.S. McGonigle, D.M. Pyle and I. Wängberg (2007). Degassing of gaseous (elemental and reactive) and particulate mercury from Mount Etna volcano (southern Italy), Atmos. Environ., 41, 7377-7388; doi: 10.1016/j.atmosenv.2007.05.060.

Bani., P., C. Oppenheimer, J.C. Varekamp, T. Quinou, M. Lardy and S. Carn (2009a), Remarkable geochemical changes and degassing at Voui crater lake, Ambae volcano, Vanuatu, J. Volcanol. Geotherm. Res., 188, 347-357; doi: 10.1016/j.jvolgeores.2009.09.018.

Bani, P., C. Oppenheimer, V.I. Tsanev, S.A. Carn, S.J. Cronin, R. Crimp, J.A. Calkins, D. Charley, M. Lardy and T.A. Roberts (2009b). Surge in sulphur and halogen degassing from Ambrym volcano, Vanuatu, Bull. Volcanol., 71, 1159-1168; doi: 10.1007/s00445-009-0293-7.

Barrancos, J., J.I. Rosello, D. Calvo, E. Padron, G. Melian, P.A. Hernandez, N.M. Perez, M. Millán and B. Galle (2008). $\mathrm{SO}_{2}$ emission from active volcanoes measured simultaneously by COSPEC and mini-DOAS, Pure Appl. Geophys., 165, 115-133; doi: 10.1007/s00024-007-0290-8.

Bluth, G.J.S., J.M. Shannon, I.M. Watson, A.J. Prata and V.J. Realmuto (2007). Development of an ultra-violet digital camera for volcanic $\mathrm{SO}_{2}$ imaging, J. Volcanol. Geotherm. Res., 161, 47-56; doi: 10.1016/j.jvolgeores.2006.11.004.

Bobrowski, N., G. Hönninger, B. Galle and U. Platt (2003). Detection of bromine monoxide in a volcanic plume, Nature, 423, 273-276; doi: 10.1038/nature01638.

Bobrowski, N., G. Hönninger, F. Lohberger and U. Platt (2006). IDOAS: A new monitoring technique to study the $2 \mathrm{D}$ distribution of volcanic gas emissions, J. Volcanol. Geotherm. Res., 150, 329-338; doi: 10.1016/j.jvolgeores. 2005.05.004.

Bobrowski, N. and U. Platt (2007). $\mathrm{SO}_{2} / \mathrm{BrO}$ ratios studied in five volcanic plumes, J. Volcanol. Geotherm. Res., 166, 147-160; doi: 10.1016/j.jvolgeores.2007.07.003.

Bobrowski, N., R. von Glasow, A. Aiuppa, S. Inguaggiato, I. Louban, O.W. Ibrahim and U. Platt (2007). Reactive halogen chemistry in volcanic plumes, J. Geophys. Res., 112, D06311; doi: 10.1029/2006JD007206.

Bobrowski, N., C. Kern, U. Platt, C. Hörmann and T. Wagner (2010). Novel $\mathrm{SO}_{2}$ spectral evaluation scheme using the 360-390 nm wavelength range, Atmos. Meas. Tech., 3, 879-891; doi: 10.5194/ amt-3-879-2010.

Boichu, M., C. Oppenheimer, V. Tsanev and P.R. Kyle (2010).
High temporal resolution $\mathrm{SO}_{2}$ flux measurements at Erebus volcano, Antarctica, J. Volcanol. Geotherm. Res., 190, 325-336; doi: 10.1026/j/jvolgeores.2009.11.020.

Burton, M.R., T. Caltabiano, F. Murè, G. Salerno and D. Randazzo (2009). $\mathrm{SO}_{2}$ flux from Stromboli during the 2007 eruption: results from the FLAME network and traverse measurements, J. Volcanol. Geotherm. Res., 182, 214-220; doi: 10.1016/j.jvolgeores.2008.11.025.

Dalton, M.P., I.M. Watson, P.A. Nadeau, C. Werner, W. Morrow and J.M. Shannon (2009). Assessment of the UV camera sulfur dioxide retrieval for point source plumes, J. Volcanol. Geotherm. Res., 188, 358-366; doi: 10.1016/j/ jvolgeores.2009.09.013.

Dalton, M.P., G.P. Waite, I.M. Watson and P.A. Nadeau (2010). Multiparameter quantification of gas release during weak Strombolian eruptions at Pacaya Volcano, Guatemala, Geophys. Res. Lett., 37, L09303; doi: 10.1029/2010GL042617.

Edmonds, M., R.A. Herd, B. Galle and C.M. Oppenheimer (2003). Automated, high time-resolution measurements of $\mathrm{SO}_{2}$ flux at Soufrière Hills Volcano, Montserrat, Bull. Volcanol., 65, 578-586; doi: 10.1007/s00445-003-0286-x.

Edmonds, M. and R.A. Herd (2007). A volcanic degassing event at the explosive-effusive transition, Geophys. Res. Lett., 34, L21310; doi: 10.1029/2007GL031379.

Edmonds, M. (2008). New geochemical insights into volcanic degassing, Philos. Trans. R. Soc. Ser. A, 366, 4559-4579; doi: $10.1098 /$ rsta.2008.0185.

Elias, T., A.J. Sutton, C. Oppenheimer, K.A. Horton, H. Garbeil, V. Tsanev, A.J.S. McGonigle and G. Williams-Jones (2006). Comparison of COSPEC and two miniature ultraviolet spectrometer systems for $\mathrm{SO}_{2}$ measurements using scattered sunlight, Bull. Volcanol., 68, 313-322; doi: 10.1007/ s00445-005-0026-5.

Galle, B., C. Oppenheimer, A. Geyer, A.J.S. McGonigle, M. Edmonds and L.A. Horrocks (2003). A miniaturised UV spectrometer for remote sensing of $\mathrm{SO}_{2}$ fluxes: a new tool for volcano surveillance, J. Volcanol. Geotherm. Res., 119, 241-254; doi: 10.1016/S0377-0273(02)00356-6.

Galle., B., M. Johansson, C. Rivera, Y. Zhang, M. Kihlman, C. Kern, T. Lehmann, U. Platt, S. Arellano and S. Hidalgo (2010). Network for Observation of Volcanic and Atmospheric Change (NOVAC) - a global network for volcanic gas monitoring: network layout and instrument description, J. Geophys. Res., 115, D05304; doi: 10.1029/2009JD011823.

Grutter, M., R. Basaldud, C. Rivera, R. Harig, W. Junkerman, E. Caetano and H. Delgado-Granados (2008). $\mathrm{SO}_{2}$ emissions from Popocatépetl volcano: emission rates and plume imaging using optical remote sensing techniques, Atmos. Chem. Phys., 8, 6655-6663; doi: 10.5194/acp-86655-2008.

Hilton, D.R., T.P. Fischer, A.J.S. McGonigle and J.M. de Moor (2007). Variable $\mathrm{SO}_{2}$ emission rates for Anatahan volcano, 
the Commonwealth of the Northern Mariana Islands: implications for deriving arc-wide volatile fluxes from erupting volcanoes, Geophys. Res. Lett., 34, L14315; doi: 10.1029/2007GL030405.

Horton, K.A., G. Williams-Jones, H. Garbeil, T. Elias, A.J. Sutton, P. Mouginis-Mark, J.N. Porter and S. Clegg (2006). Real-time measurement of volcanic $\mathrm{SO}_{2}$ emissions: validation of a new UV correlation spectrometer (FLYSPEC), Bull. Volcanol., 68, 323-327; doi: 10.1007/s00445-0050014-9.

Johansson. M., B. Galle, C. Rivera and Y. Zhang (2009a). Tomographic reconstruction of gas plumes using scanning DOAS, Bull. Volcanol., 71, 1169-1178; doi: 10.1007/s00445009-0292-8.

Johansson. M., B. Galle, Y. Zhang, C. Rivera, D. Chen and K. Wyser (2009b). The dual-beam mini-DOAS technique measurements of volcanic gas emission, plume height and plume speed with a single instrument, Bull. Volcanol., 71, 747-751; doi: 10.1007/s00445-008-0260-8.

Kantzas, E.P. and A.J.S. McGonigle (2008). Comparison of low-cost miniature spectrometers for volcanic $\mathrm{SO}_{2}$ emission measurements, Sensors, 8, 1559-1574; doi: $10.3390 / \mathrm{s} 8031559$.

Kantzas, E.P., A.J.S. McGonigle and R.G. Bryant (2009). Comparison of low-cost miniature spectrometers for volcanic $\mathrm{SO}_{2}$ emission measurements, Sensors, 9, 3256-3268; doi: $10.3390 / \mathrm{s} 90503256$.

Kantzas, E.P., A.J.S. McGonigle, G. Tamburello, A. Aiuppa and R.G. Bryant (2010). Protocols for UV camera volcanic $\mathrm{SO}_{2}$ measurements, J. Volcanol. Geotherm. Res., 94, 5560; doi: 10.1016/j.jvolgeores.2010.05.003.

Kazahaya, R., T. Mori, K. Kasahaya and J. Hirabayashi (2008). Computed tomography reconstruction of $\mathrm{SO}_{2}$ concentration distribution in the volcanic plume of Miyakejima, Japan, by airborne traverse technique using three UV spectrometers, Geophys. Res. Lett., 35, L13816; doi: 10.1029/2008GL034177.

Kern, C., H. Sihler, L. Vogel, C. Rivera, M. Herrera and U. Platt (2009). Halogen oxide measurements at Masaya volcano, Nicaragua, using active long path differential optical absorption spectroscopy, Bull. Volcanol., 71, 659670; doi: 10.1007/s00445-008-0252-8.

Kern, C., F. Kick, P. Lübcke, L. Vogel, M. Wöhrbach and U. Platt (2010a). Theoretical description of functionality, applications, and limitations of $\mathrm{SO}_{2}$ cameras for the remote sensing of volcanic plumes, Atmos. Meas. Tech., 3, 733-749, 2010; doi: 10.5194/amt-3-733-2010.

Kern, C., T. Deutschmann, L. Vogel, M. Wöhrbach, T. Wagner and U. Platt (2010b). Radiative transfer corrections for accurate spectroscopic measurements of volcanic gas emissions, Bull. Volcanol., 72, 233-247; doi: 10.1007/s004 45-009-0313-7.

Krotkov, N.A., S.A. Carn, A.J. Krueger, P.K. Bhartia and K.
Yang (2006). Band residual difference algorithm for retrieval of $\mathrm{SO}_{2}$ from the aura Ozone Monitoring Instrument (OMI), IEEE Trans. Geosci. Remote Sens., 44, 1259-1266; doi: 10.1109/TGRS.2005.861932.

Lee, C.Y., J. Kim, H. Tanimoto, N. Bobrowski, U. Platt, T. Mori, K. Yamamoto and C.S. Hong (2005). High ClO and ozone depletion observed in the plume of Sakurajima volcano, Japan, Geophys. Res. Lett., 32, L21809; doi: $0.1029 / 2005$ GL023785.

Louban, I., N. Bobrowski, D. Rouwet, S. Inguaggiato and U. Platt (2009). Imaging DOAS for volcanological applications, Bull. Volcanol., 71, 753-765; doi: 10.1007/s00 445-008-0262-6.

Mather, T.A., V.I. Tsanev, D.M. Pyle, A.J.S. McGonigle, C. Oppenheimer and A.G. Allen (2004). Characterization and evolution of tropospheric plumes from Lascar and Villarrica volcanoes, Chile, 109, D21303; doi: 10.1029/200 4JD004934.

Mather, T.A., D.M. Pyle, V.I. Tsanev, A.J.S. McGonigle, C. Oppenheimer and A.G. Allen (2006). A reassessment of current volcanic emissions from the Central American arc with specific examples from Nicaragua, J. Volcanol. Geotherm. Res., 149, 297-311; doi: 10.1016/j.jvolgeores. 2005.07.021.

Mather, T.A. (2008). Volcanism and the atmosphere: the potential role of the atmosphere in unlocking the reactivity of volcanic emissions, Philos. Trans. R. Soc. Ser. A, 366, 4581-4595; doi: 10.1098/rsta.2008.0152.

McGonigle, A.J.S., C. Oppenheimer, B. Galle, T.A. Mather and D.M. Pyle (2002). Walking traverse and scanning DOAS measurements of volcanic gas emission rates, Geophys. Res. Lett., 29, 1985; doi: 10.1029/2002GL015827.

McGonigle, A.J.S., C. Oppenheimer, B. Galle, M. Edmonds, T. Caltabiano, G. Salerno, M. Burton and T.A. Mather (2003). Volcanic sulphur dioxide flux measurements at Etna, Vulcano and Stromboli obtained using an automated scanning static ultraviolet spectrometer, J. Geophys. Res., 108, 2455; doi: 10.1029/2002JB002261.

McGonigle, A.J.S., C. Oppenheimer, V.I. Tsanev, K. Mulina, S. Tohui, J. Bosco, J. Nahou, J. Kuduon and F. Taranu (2004a). Sulphur dioxide fluxes from Papua New Guinea's volcanoes, Geophys. Res. Lett., 31, L08606; doi: 10.1029/ 2004GL019568.

McGonigle, A.J.S., P. Delmelle, C. Oppenheimer, V.I. Tsanev, T. Delfosse, G. Williams-Jones, K. Horton and T.A. Mather (2004b). $\mathrm{SO}_{2}$ depletion in tropospheric volcanic plumes, Geophys. Res. Lett., 31, L13201; doi: 10.1029/200 4GL019990.

McGonigle, A.J.S. (2005). Volcano remote sensing with ground based spectroscopy, Philos. Trans. R. Soc. Ser. A, 363, 2915-2929; doi: 10.1098/rsta.2005.1668.

McGonigle, A.J.S., D.R. Hilton, T.P. Fischer and C. Oppenheimer (2005a). Plume velocity determination for volcanic 
$\mathrm{SO}_{2}$ flux measurements, Geophys. Res. Lett., 32, L11302; doi: 10.1029/2005GL022470.

McGonigle, A.J.S., S. Inguaggiato, A. Aiuppa, A.R. Hayes and C. Oppenheimer (2005b). Accurate measurement of volcanic $\mathrm{SO}_{2}$ flux: determination of plume transport speed and integrated $\mathrm{SO}_{2}$ concentration with a single device, Geochem. Geophys. Geosyst., 6, Q02003; doi: 10.1029/ 2004GC000845.

McGonigle, A.J.S. (2007). Measurement of volcanic $\mathrm{SO}_{2}$ fluxes with differential optical absorption spectroscopy, J. Volcanol. Geotherm. Res., 162, 111-122; doi: 10.1016/j. jvolgeores.2007.02.001.

McGonigle, A.J.S., A. Aiuppa, G. Giudice, G. Tamburello, A.J. Hodson and S. Gurrieri (2008). Unmanned aerial vehicle measurements of volcanic carbon dioxide fluxes, Geophys. Res. Lett., 6, L06303; doi: 10.1029/2007GL032508.

McGonigle, A.J.S., A. Aiuppa, M. Ripepe, E.P. Kantzas and G. Tamburello (2009). Spectroscopic capture of $1 \mathrm{~Hz}$ volcanic $\mathrm{SO}_{2}$ fluxes and integration with volcano geophysical data. Geophys. Res. Lett., 36, L21309; doi: 10.1029/2009GL040494.

Moffat, A.J. and M.M. Millán (1971). The application of optical correlation techniques to the remote sensing of $\mathrm{SO}_{2}$ plumes using sky light, Atmos. Environ., 5, 677-690.

Mori, T. and M. Burton (2006). The $\mathrm{SO}_{2}$ camera: A simple, fast and cheap method for ground-based imaging of $\mathrm{SO}_{2}$ in volcanic plumes, Geophys. Res. Lett., 33, L24804; doi: 10.1029/2006GL027916.

Mori, T., K. Kazahaya, C. Oppenheimer, A.J.S. McGonigle, V.I. Tsanev, R. Olmos, M. Ohwada and T. Shuto (2006a). Sulfur dioxide fluxes from the volcanoes of Hokkaido, Japan, J. Volcanol. Geotherm. Res., 158, 235-243; doi: 10.1016/j.volgeores.2006.04.024.

Mori, T., T. Mori, K. Kazahaya, J. Ohwada, J. Hirabayashi and S. Yoshikawa (2006b). Effect of UV scattering on $\mathrm{SO}_{2}$ emission rate measurements, Geophys. Res. Lett., 33, L17315; doi: 10.1029/2006GL026285.

Mori, T. and M. Burton (2009). Quantification of the gas mass emitted during single explosions on Stromboli with the $\mathrm{SO}_{2}$ imaging camera, J. Volcanol. Geotherm. Res., 188, 395-400; doi: 10.1016/j.jvolgeores.2009.10.005.

Nadeau, P. and G. Williams-Jones (2009). Apparent downwind depletion of volcanic $\mathrm{SO}_{2}$ flux - lessons from Masaya volcano, Nicaragua, Bull. Volcanol., 71, 389-400; doi: 10.1007/s00445-008-0251-9.

O'Dwyer, M., M.J. Padgett, A.J.S. McGonigle, C. Oppenheimer and S. Inguaggiato (2003). Real-time measurement of volcanic $\mathrm{H}_{2} \mathrm{~S}$ and $\mathrm{SO}_{2}$ concentrations by $\mathrm{UV}$ spectroscopy, Geophys. Res. Lett., 30, 1652; doi: 10.1029/ 2003 GL017246.

Olmos, R., J. Barrancos, C. Rivera, R. Barahona, D.L. Lopez, B. Henriquez, A. Hernandez, E. Benitez, P.A. Hernandez, N. M. Perez and B. Galle (2007). Anomalous emissions of
$\mathrm{SO}_{2}$ during the recent eruption of Santa Ana volcano, El Salvador, Central America, Pure Appl. Geophys., 164, 2489-2506; doi: 10.1007/s00024-007-0276-6.

Oppenheimer, C., A.J.S. McGonigle, P. Allard, M.J. Wooster and V. Tsanev (2004). Sulfur, heat, and magma budget of Erta 'Ale lava lake, Ethiopia, Geology, 32, 509-512; doi: 10.1130/G20281.1.

Oppenheimer, C., P.R. Kyle, V.I. Tsanev, A.J.S. McGonigle, T.A. Mather and D. Sweeney (2005). Mt. Erebus, the largest point source of $\mathrm{NO}_{2}$ in Antarctica, Atmos. Environ., 39, 6000-6006; doi: 10.1016/j.atmonsenv.2005.06.036.

Oppenheimer, C., V.I. Tsanev, C.F. Braban, R.A. Cox, J.W. Adams, A. Aiuppa, N. Bobrowski, P. Delmelle, J. Barclay and A.J.S. McGonigle (2006). BrO formation in volcanic plumes, Geochim. Cosmochim. Acta, 70, 2935-2941; doi: 0.1016/j.gca.2006.04.001.

Oppenheimer, C. (2010). Ultraviolet sensing of volcanic sulfur emissions, Elements, 6, 87-92; doi: 10.2113/gselements. 6.2 .87

Platt, U., D. Perner and H.W. Pätz (1979). Simultaneous measurements of atmospheric $\mathrm{CH}_{2} \mathrm{O}, \mathrm{O}_{3}$ and $\mathrm{NO}_{2}$ by differential optical absorption, J. Geophys. Res., 84, 6329-6335.

Platt, U. and J. Stutz (2008). Differential optical absorption spectroscopy - principles and applications, Springer, Heidelberg, 1-597.

Rodriguez, L.A., I.M. Watson, M. Edmonds, G. Ryan, V. Hards, C.M.M. Oppenheimer and G.J.S. Bluth (2008). $\mathrm{SO}_{2}$ loss rates in the plume emitted by Soufrière Hills volcano, Montserrat, J. Volcanol. Geotherm. Res., 173, 135-147; doi: 10.1016/j.jvolgeores.2008.01.003.

Salerno, G.G., M.R. Burton, C. Oppenheimer, T. Caltabiano, D. Randazzo, N. Bruno and V. Longo (2009a). Threeyears of $\mathrm{SO}_{2}$ flux measurements of Mt. Etna using an automated UV scanner array: comparison with conventional traverses and uncertainties in flux retrieval, J. Volcanol. Geotherm. Res., 183, 76-83; doi: 10.1016/j. jvolgeores.2009.02.013.

Salerno, G.G., M.R. Burton, C. Oppenheimer, T. Caltabiano, V.I. Tsanev and N. Bruno (2009b). Novel retrieval of volcanic $\mathrm{SO} 2$ abundance from ultraviolet spectra, J. Volcanol. Geotherm. Res., 181, 141-153; doi: 10.1016/j.jvolgeores. 2009.01.009.

Sawyer, G.M., C. Oppenheimer, V.I. Tsanev and G. Yirgu (2008a). Magmatic degassing at Erta 'Ale volcano, Ethiopia, J. Volcanol. Geotherm. Res., 178, 837-846; doi: 10.1016/j.jvolgeores.2008.09.017.

Sawyer, G.M., S.A. Carn, V.I. Tsanev, C. Oppenheimer and M. Burton (2008b). Investigation into magma degassing at Nyiragongo volcano, Democratic Republic of the Congo, Geochem. Geophys. Geosyst., 9, Q02017; doi: 10.1029/2007GC001829.

Stoiber, R.E., L.L. Malinconico and S.N. Williams (1983). Use of the correlation spectrometer at volcanoes, In: Fore- 
casting Volcanic Events, H. Tazieff and J. C. Sabroux (Editors), Elsevier, Amsterdam, 425-444.

Sweeney, D., P.R. Kyle and C. Oppenheimer (2008). Sulfur dioxide emissions and degassing behavior of Erebus volcano, Antarctica, J. Volcanol. Geotherm. Res., 177, 725-733; doi: 10.1016/j.jvolgeores.2008.01.024.

Symonds, R.B., W.I. Rose, G.J.S. Bluth and T.M. Gerlach (1994). Volcanic gas studies - methods, results, and applications. Rev. Mineral., 30, 1-66.

Tamburello, G., E.P. Kantzas, A.J.S. McGonigle, A. Aiuppa and G. Guidice (2011). UV camera measurements of fumarole field degassing (La Fossa crater, Vulcano Island), J. Volcanol. Geotherm. Res., 199, 47-52; doi: doi:10.1016/ j.jvolgeores.2010.10.004.

Thordarson, T. and S. Self (2003). Atmospheric and environmental effects of the 1783-1784 Laki eruption: A review and reassessment, J. Geophys. Res., 108, 4011; doi: 10.1029/2001JD002042.

Vance, A., A.J.S. McGonigle, A. Aiuppa, J.L. Stith, K. Turnbull and R. von Glasow (2010). Ozone depletion in tropospheric volcanic plumes, Geophys. Res. Lett., 37, L22802; doi: 10.1029/2010GL044997.

Williams-Jones, G., K. Horton, T. Elias, H. Garbeil, P.J. Mouginis-Mark, A.J. Sutton and A.J.L. Harris (2006). Accurately measuring volcanic plume velocity with multiple UV spectrometers, Bull. Volcanol., 68, 328-332; doi: 10.1007/s00445-005-0013-x.

Wright, T.E., M. Burton, D.M. Pyle and T. Caltabiano (2008). Scanning tomography of $\mathrm{SO}_{2}$ distribution in a volcanic gas plume, Geophys. Res. Lett., 35, L17811; doi: 10.1029/ 2008GL034640.

Yamamoto, H., I.M. Watson, J.C. Phillips and G.J. Bluth (2008). Rise dynamics and relative ash distribution in vulcanian eruption plumes at Santiaguito volcano, Guatemala, revealed using an ultraviolet imaging camera, Geophys. Res. Lett., 35, L08314; doi: 10.1029/2007GL032008.

\footnotetext{
${ }^{\star}$ Corresponding author: Andrew McGonigle, University of Sheffield, Department of Geography, Sheffield, UK; email: a.mcgonigle@shef.ac.uk.

C 2011 by the Istituto Nazionale di Geofisica e Vulcanologia. All rights reserved.
} 